\title{
On the pitch of a tuning-fork in an incompressible fluid
}

\section{Felix Auberbach}

To cite this article: Felix Auberbach (1878) On the pitch of a tuning-fork in an incompressible fluid, Philosophical Magazine Series 5, 5:32, 395-397, DOI: $10.1080 / 14786447808639445$

To link to this article: http://dx.doi.org/10.1080/14786447808639445

曲 Published online: 13 May 2009.

Submit your article to this journal \lceil

Џll Article views: 4

Q View related articles $\sqsubset$ 
coral, with some basalt peblles and shells; 3 . Compact limestone, with thin layers of basalt at base. The author described the supposed fossil trees noticed in this island by Messrs. Ayres and Clarke (Q. J. G. S. xxiii. p. 185) as composed simply of hard portions of coral rock left outstanding by the weathering of the softer intervening parts; they show the same stratification as the rock below. The islet known as Gunner's Quoin consists of columnar basaltic lava, capping volcanic sand, below which is a browner volcanic sand with seams of coral fragments. Flat Island is in part the remains of a volcanic crater, and the rest consists of volcanic sand strewn with coral blocks. There are basaltic dykes in the hill, the top of which appcars to show traces of one or more plugs. The author concludes that Mauritius was once an active volcano, now elevated with the old reef. The islets also formed part of a volcano or volcanoes, and have also been elevated with reef-material.

LVI. Intelligence and Miseellaneous Articles.

ON THE PITCH OF A TLNING-FORK IN AN INCOMPRESSIBLE FLUID. BY FELIX AUERBACH.

W HEN a tuning-fork is struck and then quickly immersed in a vessel containing water, there is heard, especially if the ear be applied to the resonant table, a tone the height of which does not accord with that of the tuning-fork in air.

This nhenomenon, which seems to have hitherto excited but little notice (I have found a remark in reference to it only in Chladni's Akustik), follows as a necessary consequence from the fact that the dissipation of the kinetic energy takes place in the so-called incompressible fluids under other circumstances than those which subsist in gases. For into all formulæ for the velocity of propagation and for the number of vibrations enters the square-root of a quantity to which a determinate signification cannot at once be assigned. In fact the coefficient of elasticity is usually defined merely as the ratio of an infinitesimal increment of pressure to the corresponding infinitesimal compression of volume; yet its value essentially depends on what are the circumstances under which the change of state in question proceeds. Of special importance are two casesnamely, that in which the entropy of the system. and that in which the temperature remains constant. With the sonorous vibrations of elastic solid bodies in gases the first of these cases is approximately realized. For the alternate condensations and rarefactions undergone by the gas have, it is true, for their consequence changes of the temperature; hence, in the equalization of this, kinetic energy is given up to the environment; but the conductivity of gases for heat is so inconsiderable that the dissipation of energy can be neglected for rapid vibrations like those of sound: for these, according to Clausius, it may even be said that the entropy remains 
constant. The other case is to a certain degree of approximation realized when the solid body vibrates in a liquid the surface of which is in part free (that is, bounded by an elastic fluid). As in the other case the variations of the entropy were negligible, so in this are the changes of temperature, and, indeed, for three reasons. In the first place, the condensations are very slight; therefore no molecular energy is generated. Secondly, the specific heat of water is very great; consequently the temperature is disproportionately little altered. And, thirdly, the conductivity of water for heat is not so inconsiderable that a considerable part of the changes of temperature which might by chance take place would not be again eliminated by equalization.

The two values of the coefficient of elasticity in these two cases are in the same proportion to each other as the two values possessed by the specific heat, according as the pressure or the volume remains constant. This ratio does not materially differ from $1 \cdot 4$.

From these considerations the nature and quantity of the change of tone can be deduced which took place in the experiment mentioned at the commencement. The tone must become deeper; for with the temperature constant the elasticity is less than with a constant entropy; and the tones in air and in water must be proportional to one another as $\sqrt{\mathbf{1} \cdot 4}: 1, i$. e. as $1 \cdot 18: 1$, or about as $7: 6$. The interval must therefore be greater than an entire tone, and less than a minor third.

Indeed experiments show that the interval approximates to this value required by theory as a maximum. That on the average it is somewhat less (viz. for the middle notes exactly a complete tone) is not surprising when it is remembered that the above considerations hold for two ideal extreme cases, between which lie those of vibrations in air and in water. For a few tones I have determined the deepening by making use of the beats which are heard when simultaneously with the fork immersed in water another fork, the tone of which is a complete interval deeper than the tone in air of the experiment-fork, is set vibrating in air. In this way I found for the ratio of vibration with the following tones the values placed under them.

\begin{tabular}{|c|c|c|c|}
\hline$c$ (132 vibr. $)$ & $c_{1}(264$ vibr. $)$ & $g_{1}(396$ vibr. $)$ & $c_{2}(528$ vibr. $)$. \\
\hline $1 \cdot 11(<9: 8)$ & $1 \cdot 12(9: 8)$ & $1 \cdot 13(<8: 7)$ & $1 \cdot 15(>8: 7)$ \\
\hline
\end{tabular}

The result derived from these numbers, namely that the ideal extreme value of the interval is the more closely approximated to the higher the tone (i.e. the shorter the period of vibration), agrees, according to the foregoing, with the theory.

In conclusion, I have instituted some control-experiments with other liquids. From these it follows that the influence of the resistance of the liquids, which depends on their density and viscosity, and which is very important for the amplitude and the logarithmic 
decrement of the tuning-fork's vibrations, does not sensibly come into consideration with respect to the length of a vibration-not even in the cases of mercury and glycerine, although in the former the density, and in the latter the viscosity is very great.-Annalon der Physik und Chemie, 1878, No. 1, pp. 157-160.

A NOTE ON EXPERIMENTS WITH FLOATING MAGNETS ; SHOWING THE MOTIONS AND ARRANGEMENTS IN A PLANE OF FREELY MOVING BODIES ACTED ON BY FORCES OF ATTRACTION AND REPULSION, AND SERVING IN THE STUDY OF THE DIRECTIONS AND MOTIONS OF THE LINES OF MAGNETIC FORCE. BY ALFRED

\section{MAYER.}

For one of my little books of the Experimental-Science Series I have devised a system of experiments which illustrate the action of atomic forces, and the atomic arrangement in molecules, in so pleasing a manner, that I think these experiments should be known to those interested in the study and teaching of physics.

A dozen or more of No. 5 or 6 sewing-needles are magnetized with their points of the same polarity, say north. Each needle is run into a small cork, $\frac{1}{4}$ in. long and $\frac{3}{16}$ in. in diameter, which is of such size that it just floats the needle in an upright position. The eye end of the needle just comes through the top of the cork.

Float three of these vertical magnetic needles in a bowl of water, and then slowly bring down over them the north pole of a rather large cylindrical magnet. The mutually repellent needles at once approach each other, and finally arrange themselves at the vertices of an equilateral triangle, thus $\therefore$ The needles come nearer together or go further away as the magnet, above them, approaches them or is removed from them. Vibrations of the magnet up and down cause the needles to vibrate; the triangle formed by them alternately increasing and diminishing in size.

On lifting the magnet vertically to a distance, the needles mutually repel and end by taking up positions at the vertices of a triangle inscribed to the bowl.

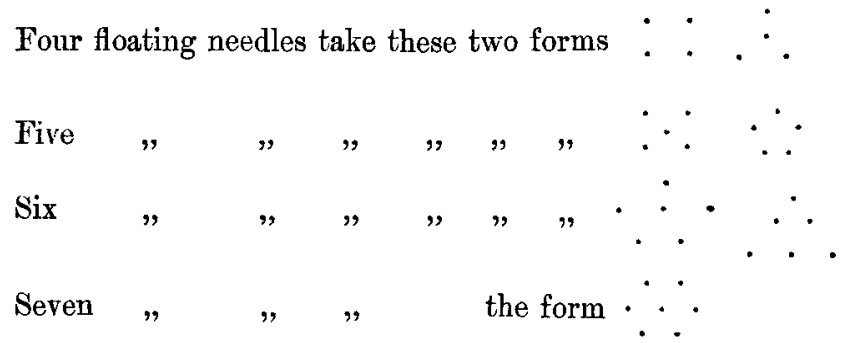

I have obtained the figures up to the combination of twenty foating needles. Some of these forms are stable; others are unstable, and are sent into the stable forms by vibration. 